\title{
LOGISTICS DURING POPULATION AND ANIMALS EVACUATION IN CASE OF EXTRAORDINARY INCIDENTS AND CRISIS EVENTS
}

\begin{abstract}
Evacuation is one of the main tasks of administration and its forces and resources in different types of extraordinary events, as well as natural and anthropogenic (non-military and military events) unusual/emergency situations. Evacuation at the level of normative acts and plans is precisely defined and categorized. Existing normative documents and regulations are described in detail and govern to carry out the evacuation of population. This is not the case for animal and property evacuation, which is often treated in general terms and considered to be organized in similar manner to evacuation of people. In the evacuation process of animals, the specific of this process must be taken into account, because badly prepared and performed evacuation may bring more harm than benefit. Hence, the aim of this article is to present, selected essential and specific issues relating to the evacuation of animals, based on theory provisions of the normative and practical experience of the authors.
\end{abstract}

Keywords: logistics, evacuation, evacuation degrees, danger, risk, population, animals

\section{Introduction}

According to the Constitution of the Republic of Poland, the source of law in Poland are laws and regulations, as well as ratified international agreements. Thus, they become the basis for planning and realizing the evacuation of people, animals and property in the event of danger to their safety. The international agreements ratified by Poland concerning evacuation include: the IV Geneva Convention, and the I and II Additional Protocols to the Geneva Conventions.

Under the national law, the basic arrangements for evacuating the population are laid down in the regulations of the Council of Ministers, where it has been stipulated that the heads of civil defence are responsible for the preparation, organization and management of evacuation. The arrangements referring to dates, to evacuation routes and evacuation locations are subject to agreement with the relevant authorities and services and all the preparations and their implementation should be in accordance with the regulations of the Chief of Civil Defence of the Country (SOCK), dated $17^{\text {th }}$ of October 2008 [1], which are guidelines on the principles of evacuation of the population, animals and property in the event of a mass threat, and annex to these guidelines in the form of the Instructions on the principles of evacuation of the population, animals and property in the event of a mass threat. The subject-related guidelines cover the provisions of all the so-far-existing evacuation acts, as well as the theory and practice of planning and executing evacuation.

\section{Theoretical and legal aspects of evacuation}

In the theory of the tackled issue there are many definitions of evacuation, which distinguish the evacuation of people, animals, property, objects, as well as the evacuation of specific character: medical, technical, veterinary, war and military activities. However, they all have a common denominator, namely the movement of people, animals and property from the threatened to safe areas.

Evacuation (lat. evacuatio - emptying, disappearing) in general is one of the basic measures, which aims at protecting life and health of humans, animals and saving property, including antiques and important documentation, in the occurrence of any kind of threat. It is usually carried out in the form of relocation from a region (site) where the danger occurs, to the safe area. In practice, most frequently the evacuation is carried out for the injured or those at risk (including animals and property at risk) after the occurrence of a hazardous event (e.g. flood, fire,

\footnotetext{
* ${ }^{1}$ Marcin Paweska, ${ }^{2}$ Jozef Ristvej

${ }^{1}$ International University of Logistics and Transport in Wroclaw, Poland

${ }^{2}$ Department of Crisis Management, Faculty of Security Engineering, University of Zilina, Slovakia

E-mail: Jozef.Ristvej@fbi.uniza.sk
} 


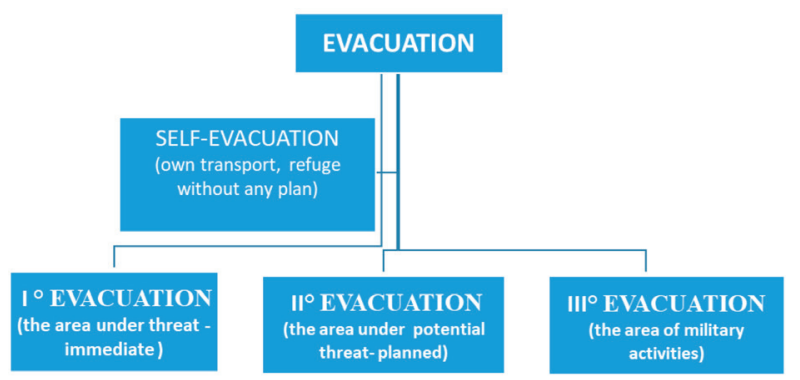

Figure 1 The degrees of evacuation

explosion or other local threat) in objects or areas affected by the incident, that is, the area already covered by the emergency event. Evacuation can also be of the preventive nature, i.e. it can be carried out from areas and facilities in the event of an imminent threat, e.g. due to the spread of dangerous events (flood, chemical catastrophe, etc.) or the threat of military action in the case of war risks..." [2], [3]. However, the author of this definition also only perfunctorily deals with animals in the first part of the discussion [2].

The definition which took into account all the basic aspects of evacuation has been presented by K. Przeworski, who defined it as "... organized movement (removing, taking out, moving) of the population, all kinds of material goods and farm animals from areas or facilities threatened or affected by armed forces or disasters, in order to protect them, to provide assistance, also understood as rescue and limitation of material losses..." [4].

Due to the nature and scale of the threat, the evacuation of I, II and III degree is distinguished [5] (Figure 1).

The individual degrees of evacuation consist of:

- I degree evacuation involves immediate relocation of the population, animals and property outside the threatened area where sudden, unforeseen direct threats occurred. It is organized at the mayor's or the city president's order. Evacuation may also be ordered by the person conducting the rescue operation in the area where rescue operations take place. The leader of the rescue operation is obliged to inform the competent self-government administration about the decision taken. The I degree evacuation can be carried out based on documentation prepared for the II degree evacuation;

- II degree evacuation is the planned relocation of the population, animals and property from the adjacent areas to plants, hydro-technical facilities, floodplains and areas adjacent to other facilities that pose a potential threat to the population, animals or property in the event of their destruction or failure. It is implemented in the presence of symptoms of such a threat, according to previously developed plans and procedures;

- III degree evacuation means the previously planned and prepared relocation of the population, animals and property, while heightening the states of defence preparedness. It is run during the threat to the state security and war. Preparation
Table 1 Forms of evacuation

\begin{tabular}{ll}
\hline \multicolumn{2}{c}{ EVACUATION } \\
CRITERIA OF DIVISION & FORM \\
\hline $\begin{array}{l}\text { According to the form of the } \\
\text { process }\end{array}$ & - scattering \\
& - co-location (leading out) \\
& - pulling back (moving away) \\
& - evacuation transit \\
& - anarchic (escape) \\
& - lifesaving \\
According to the occurrence & - preventive \\
of threat & - alarm \\
mode & - successive (by stages and batches) \\
According to the target & - people \\
(destination) & - animals \\
& - materials \\
According to the & - cultural resources, archives, \\
organizational preparation & - planned \\
According to people's motives & - interim \\
& - natural (self-evacuation) \\
\hline
\end{tabular}

of the evacuation associated with the war time includes the following variants:

- organizing the evacuation from the anticipated areas (sites) of the operational activities of the Armed Forces;

- organizing the evacuation of the population, which expresses the desire to leave areas potentially threatened by military activities [6].

Each of these evacuation degrees may, depending on the circumstances, be implemented in by means of various forms, the details are presented in Table 1 [4].

As far as the population is concerned, all those who are in the area of danger are evacuated. The first and foremost, evacuation includes among others: mothers and children, pregnant women, people with disabilities, people from health centres, from orphanages, hospitals for chronic and incurable illnesses, beneficiaries of social care etc. Depending on the type of evacuation, the following people might not be subject to it: people involved in rescue organizations, civil protection and law enforcement services; people essential for ensuring the continuity of the life of the local community; people assigned to armed forces or armed formations not included in the armed forces; officers of armed formations not included in the armed forces (The Internal Security Agency, the Border Guard, the Government Protection Bureau, etc.); people who have been assigned the allocation to a unit destined for militarization or a militarized unit; individuals who have been assigned for civil defence formation; those necessary for the area due to the tasks performed by the armed forces. 
Table 2 Gradation of time and sort of the logistics services for the affected

\begin{tabular}{|c|c|c|c|c|c|c|}
\hline Time lapse & $\begin{array}{c}1^{\circ} \\
\text { in order }\end{array}$ & $\begin{array}{c}2^{\circ} \\
\text { in order }\end{array}$ & $\begin{array}{c}3^{\circ} \\
\text { in order }\end{array}$ & $\begin{array}{c}4^{\circ} \\
\text { in order }\end{array}$ & $\begin{array}{c}5^{\circ} \\
\text { in order }\end{array}$ & $\begin{array}{c}6^{\circ} \\
\text { in order }\end{array}$ \\
\hline Т 6 & & & & & & well-being services \\
\hline T 5 & & & & & low-line articles & \\
\hline $\mathrm{T} 4$ & & & & $\begin{array}{c}\text { deliveries of } \\
\text { water and food }\end{array}$ & & \\
\hline T 3 & & & EVACUATION & & & \\
\hline T 2 & & transport & & & & \\
\hline T 1 & medical help & & & & & \\
\hline
\end{tabular}

Both evacuation and self-evacuation should be planned within the evacuation of I, II and III degree [5]. Self-evacuation refers only to the population and consists of moving from areas where there is, or may appear, an immediate threat to life and health, to the outside of the threat area. It is mainly executed based on one's own, individual possibilities (transport, accommodation, etc.). It can take place even before the decision to evacuate, as well as while it lasts. In this context, particular attention should be paid to the following: estimation of the possible scale of self-evacuation; identification of potential directions and self-evacuation areas including family relationships, recreational plots, accommodation (in designated housing resources - holiday homes, boarding houses, hotels, residence at families residing in the distribution area); designation of escape routes and traffic management; providing fuel and technical assistance on evacuation routes; providing supplies of water, food and medical assistance.

In order to increase the effectiveness of the evacuation authorities' operations, in the evacuation areas, on the evacuations routes and at destination points, the following are organized:

- information and registration teams;

- the evacuated gathering teams;

- loading for means of transport teams;

- medical assistance teams;

- logistical assistance teams, including technical assistance;

- unloading teams;

- distribution teams [5].

The essentials of the evacuation arrangements presented confirm the thesis that most of them refer to evacuation of the population, while evacuation of animals and property is treated "“on the fly".

Animal evacuation, the same as population evacuation, is a complex process requiring appropriate planning and organization. Both evacuations have many common and cohesive features, such as the fact that evacuation of animals can also be divided into I, II and III degrees, but it is difficult to imagine selfevacuation.

However, it is important to note here that there is a need to strictly adhere to the principle that human life is a greater value and that it should be rescued in the first place. At the next stage of the evacuation, depending on the development and the state of the threat, animals and material possessions are saved.

\section{The needs of evacuation}

In the case of extraordinary events, especially in times of floods and fires, as it results from the experience, the catalogue of needs in providing help to the affected is really broad as far as logistics needs are concerned. Ensuring safety to the affected and protection of life and health have always been the priorities. Considering all the needs according to their importance and urgency, they can be hierarchically defined as providing services in the following way [3]:

- medical help and healthcare,

- transport,

- evacuation,

- deliveries of drinking water and foods,

- delivering of the low-line articles,

- well-being services.

The order and urgency of providing the above mentioned logistics services always results from the situation, e.g.: during the 1997 flood, as the first and most urgent were deliveries of water and foods, as well as evacuation. Gradation of time and sort of the logistics services for the affected are presented in Table 2 .

Ensuring safety and proper realisation of the logistics help for the affected requires advance planning, with generated risk of the extraordinary events and their primary and secondary results as the base.

\section{Planning and organization of population and animal's evacuation}

Planning for evacuation activities is the duty of all the authorities responsible for public safety. To ensure smooth and efficient operation and proper coordination of evacuation, in accordance with the regulations resulting from "the Instruction of evacuation of the population, animals and property in the event of a mass threat" issued by SOCK, it is necessary to 
prepare the Evacuation Plan as part of the Crisis Management Plan (I and II degree Evacuation) and the Civil Defence Plan (III degree Evacuation). Such a plan should specify both the manner of evacuation, depending on the existing conditions, and the resources needed to carry out the task. The condition for the effectiveness of this plan is its validity, which must be verified by means of regular inventory-taking and updating resources, as well as verification of adopted solutions.

The II and I degree Evacuation Plan, which is the part of the Crisis Management Plan, is developed by Crisis Management Teams at specific levels of administration. It consists of a descriptive and graphic parts and should contain [5]:

- Objects and areas intended for evacuation, depending on the possible hazards,

- Criteria for the selection of people for the evacuation, including the order of evacuation, for people who, for various reasons, are not subject to evacuation (if this is the case),

- Estimation of the possible scale of self-evacuation, including directions and locations of relocation,

- Criteria for the decision to evacuate, and the people (units) authorized to announce the evacuation,

- Evacuation announcement ways (techniques),

- Routes and destination locations of evacuated people and property,

- People (groups, teams, formations etc.) responsible for evacuation (people responsible for the designation of evacuation locations for individual populations and indication of the way and routes of movement, according to schedule or in an interim way);

- Places (points) of collection of evacuees,

- Loading points for means of transport and unloading points,

- Distribution locations (points),

- Detailed lists and methods of delivering tasks performed at designated points by individual teams,

- Protection of abandoned areas,

- Lists of planned means of transport, selected places of temporary residence and source of acquisition of materials and means of logistic and mode of obtaining them,

- The return of people and property to places of permanent residence or location after the end of the threat, organization of communications and traffic management,

- other data as needed.

No separate evacuation plan is developed for evacuation of the I degree, the evacuation measures of this stage are included in the II degree evacuation plan, annexed to the Emergency Management Plan, at various levels of public administration and self-government. In the case of the development of the III Degree Evacuation Plan, the main planning effort rests with the civil defence $(\mathrm{CD})$ bodies responsible for drawing up civil defence plans. The III degree evacuation plan is a subject to agreement with the armed forces, police, border guards, non-governmental organizations, Polish Railway Lines, telecommunications, neighbouring $\mathrm{CD}$ entities (for example the province $\mathrm{CD}$ plan should be agreed with the province authorities of neighbouring provinces) and the supreme head of the civil defence. It is signed by the head of the CD unit (e.g. at the province level head of the regional security and crisis management department) and approved by the CD head of a given level (e.g. the province level).

The organ for planning evacuation of animals at the provincial level is the Provincial Veterinary Doctor and at the county level the relevant services subordinate to him/her and cooperating with them [3]. In order to accomplish this task, a relevant animal evacuation unit (team) is formed at the meeting of the Crisis Management Team (CMT), which consists of the functionaries designated by the chairman of the CMT. The created organ/ team can be extended and other employees can join (depending on needs). The principle of expanding the team is the same as in the case of the population evacuation, in particular that in the context of widely understood evacuation, projects involving the evacuation of populations and animals, in principle, are carried out in parallel. The tasks of the Animal Evacuation Team include:

- Preparation of the fiat - the relevant CD Chief - regarding evacuation (adoption) of

- animals, which specifies:

- areas being evacuated, evacuation routes and areas to which the movement of animals will take place;

- manpower and equipment necessary to accomplish the task;

- the way to provide veterinary aid for the evacuated animals, the distribution and the necessary supplies;

- the organization of cooperation with, among others, military authorities, police, Polish Railway Lines, Polish Telecommunications, Province Veterinary Inspectorate and the CD Heads of neighbouring provinces;

- the organizational elements of animal's evacuation in the communes involved in the evacuation process;

- the date of completing the evacuation;

- other factors to be considered in planning and organizing the evacuation process.

- Developing animal's evacuation (adoption) plan, which is agreed upon according to the needs of the evacuated livestock with the military authorities, the police, the Polish Railway Lines, the province management of the Polish Telecommunications, the provincial veterinary inspection, the $\mathrm{CD}$ heads of the neighbouring provinces and the Chief Veterinary Officer of the country.

Animal evacuation is generally carried out in parallel with evacuation of the population. In this process, organizational units, which provide veterinary care, transportation, living conditions, order and security, are involved. For evacuation, the available means of transport (short distances) are used, and only as the last resort animals are flogged [7].

Evacuation of both the population and animals or property must be recorded, depending on the degree and scale of the 
evacuation. Evacuation cards should be pre-numbered forms and prepared along with the Evacuation Plan. In recording procedures, the use of record cards and evacuation cards has to be taken into consideration. The following rules should apply as far as the circulation of record documents are concerned [5]:

- Evacuation card:

- the card consists of three parts: A, B and C,

- evacuation cards are issued by the record and information teams in the municipality (district) appropriate for the place of actual stay of an evacuee,

- part B of the card remains at the disposal of the said units, the remaining two parts are given to the person being evacuated,

- after arriving at the place of temporary accommodation, the evacuated person hands in part $\mathrm{C}$ of the evacuation card to the record and information team in the municipality (district) appropriate for this place,

- part A of the card remains at the disposal of the person who collected it, if the evacuation card cannot be collected in the municipality (district) appropriate for the place of actual stay, the evacuee applies in order to receive the evacuation card to the team of temporary accommodation,

- Record cards of evacuated people, groups of evacuated people, evacuated animals and evacuated property:

- they are prepared by the record and information teams in municipalities (districts) appropriate for the place of actual residence of people, animals or location of property, according to the municipalities (districts) to which the person or property will be evacuated,

- copies of the relevant records are forwarded to the information and record teams in the municipality(ies) to which the person or property is evacuated, where they are compared with the actual state of the people and property, and they are completed and/or corrected as needed,

- in the case of not being able to deliver a copy of the record card, the obligation to prepare it is transferred to the records keeping teams in the municipalities (districts) appropriate for the place of temporary accommodation or movement,

- copies of the evacuation cards should also be sent to the record and information teams at higher levels of administration involved in the evacuation of given groups of people or property.

\section{Executing Evacuation}

In the case of evacuation of the I and II degree, the decision to conduct it, depending on the type and scale of the threat, is taken by [4]:

- mayor, president of the citymayor from areas directly threatened;

- bodies that supervise the operations to prevent the effects of a natural disaster, or to remove such a disaster's effects removal (during the state of a disaster); depending on the area covered by the disaster, these are:

- mayor, city president - if the state was introduced only in the municipality,

- mayor - if the state was introduced in the area of more than one commune constituting the county,

- duke - if the state of natural disaster was introduced in the area of more than one county constituting the province,

- minister appropriate for internal affairs, if the state of disaster was introduced in the area of more than one province

- duke in the case of radiation incidents of provincial coverage;

- minister appropriate for internal affairs, in the case of national radiation incidents;

- the person who supervises the rescue operation, by means of informing the affected area of the appropriate public authority (civil defence).

- In the last case mentioned above, the person in charge of the rescue operation is obliged to inform each time the competent civil defence authority of the decision made, stating:

- the area, region, facilities or complex of buildings for which the evacuation was ordered,

- the type of threat that has been the determining factor in evacuation,

- the estimated number of evacuees.

It is up to the local authority to provide the conditions necessary for evacuated and injured population and for evacuated animals to survive.

In the case of necessity of evacuation of the III degree, the decision to conduct it in accordance with the law in power is taken by the public administration bodies, i.e. the competent civil protection body or the military unit in the direct combat area

\section{The specificity of logistics of animal's evacuation}

Animal evacuation, like population evacuation, is a complex process requiring appropriate planning. Both evacuations have many common features. Evacuation of the I, II and III degree also takes place while evacuating animals. The I degree evacuation, if it needs to be performed, does not differ from the procedure of evacuation of the population. It is the responsibility of the hosts of the facility (hosts) in which the livestock is located. Often the evacuation of animals is carried out in parallel with the evacuation of the population, hence the convergence of the rules of conduct. A properly prepared evacuation plan for animals should include information on the order of departure and on their location. Evacuation of animals in urgent cases, i.e. evacuation of the I degree, is not easy and requires proper preparation, therefore it is carried out only if it does not present a direct threat to the lives of people performing this task. The construction of buildings does not always allow capable rescue operations and evacuation. In case of evacuation from a building 
on fire, flammable structural elements already covered by fire may prevent entering into the building. The low ceilings can cause dense smoke in rooms. Existing baffles can force rescuers to walk the animals individually, etc.

Evacuation of animals is a difficult and demanding task, and therefore it is important to acquire the appropriate knowledge and skills in this area and to prepare specialist equipment for rescuers and managers, because unlike humans, animals will usually follow their instinct rather than think rationally. During the evacuation, one must not ignore the fact that animals feel dread and anxiety when in danger. Moreover, they are less resistant to smoke. In the case a factor threatening and animal enters the room, an animal often lies on the ground, making it difficult to evacuate. Therefore, the evacuation of animals should begin as soon as the first signs of possible danger appear, i.e. as soon as possible. It is worth remembering to approach animals from the front, calmly, carefully and gently speak to them. They sense the frustration of the rescuer and it is easily spread. Animals walked out of an endangered area should be directed to safe places, which they cannot leave on their own will. It should also be taken into consideration that depending on the evacuated species, different activities are undertaken. For example, horses and cows shall simply be moved out of pits, but poultry shall "get out" in bags (quickly release it and provide fresh air) or in baskets. Small pets are brought out in cages.

Evacuation takes place in the land of the municipality, county and province, and if necessary to neighbouring counterparts, with whom appropriate agreements should be signed.

Evacuation should not be planned or led to:

- areas in close proximity to major industrial, transportation and military facilities;

- areas of foreseen and conducted warfare;

- areas of anticipated hazards (e.g. floods, fires, etc.).

In the process of evacuation, organizational units should provide veterinary care, transportation, living conditions, order and security. For evacuation, the available means of transport used (mainly railways - for long distances, e.g. between provinces and vehicles for shorter distances) are used. In the absence of adequate quantities, the evacuation is carried out combining allocated and own means, and flogging animals shall be done only as an ultimate solution.

Evacuation locations should be characterised by [5], [8]:

- situation on a small elevation, and in the case of planned evacuation, consideration should be given to the location of animals in other farms away from activities such as e.g. warfare;

- the possibility of providing a quick makeshift fence;

- providing conditions for watering and feeding animals;

- at least $50 \mathrm{~m}$ away from slaughterhouses, as well as agricultural and food processing buildings, rendering plants and feed mills;
- providing the possibility to protect against insects and rodents;

- smooth, paved and severed surface of the inside pads;

- durable and easy to maintain walls and floors of buildings, and the ability to disinfect them.

Moreover, the designated collection sites should have [5], [9]:

- equipment for loading and unloading animals;

- drinking water access;

- a sewage system capable of carrying out decontamination and waste removal;

- equipment for watering and feeding animals;

- animal testing station, equipped with a wash basin and a device for immobilization of animals at the time of the test, coops for sick or suspected of being sick animals, with a separate sewage system;

- a separate and properly located manure storage area;

- devices and equipment necessary for cleaning and disinfection of rooms as well as a warehouse for storing equipment and disinfectants;

- storage room for storage of animal feed;

- social-living rooms for keepers.

Evacuation of animals is a difficult task, requiring proper preparation, therefore it is only carried out if it does not pose a direct threat to the lives of rescuers and keepers of animals [8].

The evacuation of animals should be started by people who handle those animals on a daily basis [9]. Before the evacuation, rescuers should recognize the way animals are placed and tied. In large breeding facilities the evacuation plans should be prepared, including information on the locations of the animals and the sequence of their removal. In the case of tying animals, the chains should be released, trying to expel the group of animals from the room to prevent them from spreading around the facility. It often happens that in the herd there is the order of precedence. In this case, it should be kept during the rescue work. Evacuation methods are always defined by rescuers, with the use of the experience of the evacuated animals' keepers.

The experiences of the Authors of this publication during the floods of 1997 and 2010, the analysis of fires of farm buildings, especially of the breeding ones, and materials based on practical experience, elaborated mainly by the State Fire Service (PSP) and designed for the training of rescuers [9], allow to formulate the basic principles of dealing with animals during the evacuation:

- animals should be approached calmly from the head, no fear or anxiety should be shown, because the same behaviour can occur among them (do not approach the back of animals, especially the large ones such as horses);

- animals kept in the group or tied (chains, ropes) should be released as soon as possible;

- it must be kept in mind that animals are attached to their place of residence, so they often try to return to places where they have been evacuated from, so that the evacuation area must be protected so that they cannot leave; 
- large and strong individuals should be walked out by several rescuers, often with the help of their owner, and in the case of bulls only by their caretakers, rescuers as "strangers" may be treated as "enemies";

- young animals and individual species should be evacuated separately, in case of taking the young ones from their mothers, the reaction of adult animals should be closely monitored;

- In the case of herd animals, if possible, "herd leader" (indicated by the owner/keeper) shall be evacuated first, so that the whole herd would follow.

As evacuations are generally for domestic animals, reared on home farms and specialized farms, additional remarks may be done referring to the evacuation of their basic species, i.e. horses, cows, pigs, sheep and poultry. These remarks result from own observations and the analysis presented in [8], [9].

While rescuing horses one should not approached them suddenly from behind. Young, strong horses, especially stallions, should be led by their keepers. Individuals accustomed to the harness can wear a harness and be calmly walked out. Horses led next to the stress-causing places should have their eyes covered with a sack or a cloth. In order to eliminate odours, a little manure can be applied close to the nostrils.

The evacuation of cows is similar to the evacuation of horses. However, careful attention should be paid to walking breeding bulls out of the threatened areas. If strangers approach, they can take a defensive attitude and even attack. The safest way to evacuate a bull can be with a stick attached to the nose ring.

Pigs are usually evacuated without much trouble by pushing into designated areas. The problem can be sows feeding piglets, which usually do not want to leave them. In this case, the piglets should be collected in bags or baskets, and the sow is then placed behind the piglets.

In addition, the poultry shall be rescued in sacks or baskets. When picking up from an endangered place, poultry should be released as quickly as possible from the bags so that there is no suffocation risk due to insufficient amount of air.

The evacuation of sheep can cause considerable problems, because sheep naturally fall into a circle or group in the corners of the rooms. It is important to lead the flock leader, after which the sheep usually follow.

In addition to the evacuation of animals from farm buildings and adjacent facilities, evacuation of animals endangered by flood: from quagmires, mudslides, marshes and deep excavations, trees, poles, roofs shall be also taken into consideration, [8]. Rescue of animals threatened by flood does not usually cause major problems. This is done mainly by farmers themselves. Difficulties arise mainly when they need to be rescued from rooms flooded with water or on fire. To save an animal, it is often enough to free them from closure or tether. The animal rescues itself. To rescue animals trapped in trenches, swamps the most common equipment and tools are used. They can be: cranes, pneumatic pillows, tripods with blocks, rods, ropes. During the evacuation some veterinary advice may come in priceless.

\section{Conclusions}

Evacuation is a very important undertaking in the event of an emergency that threatens the safety of people, animals and property. It is performed according to a plan, following previously prepared evacuation Plans or on interim bases, if necessary. The existing legal regulations in power clearly identify the responsible people and evacuation rules. The supreme principle resulting from normative documents and the practical realization of evacuation, implicitly orders to rescue in the first place the lives of people, as the highest good, and only later animals and property.

The evacuation process as a multi-stage one must be well prepared (plans, procedures) and logically secured, especially in the case of evacuation of animals, which unlike humans, need special loading and unloading and transportation facilities.

The evacuation of animals, especially farm animals, in practice is almost in parallel with the evacuation of the population. However, it is characterized by the specificity resulting from the instinctive behaviour of particular animal species in the face of threat. Therefore, rescuers of animals must take into account the specifics of their often unnatural behaviour resulting from fears and unrest in a new unnatural situation. The specificity of the evacuation of the animals is also connected with the necessity of proper preparation of rescuers, and the use of the equipment adapted accordingly, which is not always available.

Therefore, it seems appropriate to improve the rules and prepare owners of animals and rescuers, as well as equipment for the efficient conduct of the evacuation of animals. It would also be advisable to consider the evacuation of wild animals in special farms (e.g. fox or bison farms, etc.) and in zoos, where the multiplicity and diversity of species can greatly complicate their evacuation. Another question is a human factor, more references regarding [10].

\section{Acknowledgments}

This article was created as a one of project outcomes of work co-funded by the Slovak Research and Development Agency under the contract No. SK-CN-2017-0023 Enhancing Cooperation of the Ningbo University of Technology and the University of Žilina in research, innovation and cooperation within the topic of "Intelligent Transport Systems".

The views expressed, however, are solely those of the authors and not necessarily those of the institutions with which they are affiliated or of their funding sources. The authors are solely responsible for any errors or omissions. 


\section{References}

[1] Guildlines of Civil Protection Force of 17 October 2008 on Rules for Evacuation of People, Animals and Property in Case of Mass Crisis Situation.

[2] NOWAK, E.: Logistics in Crisis Situations. AON, Warszawa, 2005.

[3] FICON, K.: Crisis Logistics. BELStudio, Warszawa, 2011.

[4] PRZEWORSKI, K.: Evacuation as a Mean to Protect People. AON, Warszawa, 2002.

[5] Instruction on the Rules of Evacuation of People, Animals and Property in case of Main Crisis. Warszawa, 2008.

[6] SIENKIEWICZ-MALYJUREK, K., KRYNOJEWSKI, F. R.: Crisis Management in Public Administration. Difin, Warszawa, 2010.

[7] BIELICKI, P.: Evacuation of People, Animals and Property. Training materials of State Fire Service, Ostrow Wlkp., 2016.

[8] SURALA, Z.: Training Materials for Fireman. Centrum Naukowo-Badawcze Ochrony Przeciwpozarowej im. Jozefa Tuliszkowskiego, 2009.

[9] Exerpt from Council Regulation (EC) No 1/2005 of 22 December 2004 Related to Protection of Animals during Transport and Related Operations.

[10] ZANICKA HOLLA, K., MORICOVA, V.: Human Factor Position in Rise and Demonstration of Accidents. Communications Scientific Letters of the University of Zilina, 13(2), 49-52, 2011. 